\title{
Cobalt on carbon nanofiber catalysts: auspicious system for study of manganese promotion in Fischer-Tropsch catalysis
}

\author{
G. Leendert Bezemer, ${ }^{a}$ Uwe Falke, ${ }^{b}$ A. Jos van Dillen ${ }^{a}$ and Krijn P. de Jong*a \\ Received (in Cambridge, UK) 23rd September 2004, Accepted 18th November 2004 \\ First published as an Advance Article on the web 23rd December 2004 \\ DOI: $10.1039 / b 414788 j$
}

\begin{abstract}
STEM-EELS and XPS investigation shows manganese oxide to be closely associated with cobalt nanoparticles supported on carbon nanofibers thereby improving selectivity in FischerTropsch catalysis.
\end{abstract}

Carbon nanofibers and carbon nanotubes, due to their small dimensions, large aspect ratio and tunable density, are a very promising material with a potential use in many applications. ${ }^{1}$ Moreover, the combination of a high mechanical strength with a high purity of graphitic carbon makes them very suitable for use as supports in heterogeneous catalysis. ${ }^{2}$ Recently, we reported the interesting catalytic performance of dispersed cobalt on carbon nanofibers catalysts for the Fischer-Tropsch (FT) reaction. ${ }^{3}$ In the FT reaction synthesis gas $\left(\mathrm{CO} / \mathrm{H}_{2}\right)$ is converted into transportation fuels, enabling the switch from crude oil to methane, coal or biomass. In this paper, we report on the remarkable influence of manganese oxide promotion on cobalt based FT catalysts, showing that manganese, although deposited in a separate step, is preferentially located on top of the cobalt particles and thus brings about strong promoter effects.

Fishbone-type carbon nanofibers (CNF) with diameters of about $30 \mathrm{~nm}$ were grown out of synthesis gas and subsequently activated by refluxing them in concentrated $\mathrm{HNO}_{3}$ using established procedures. ${ }^{4,5}$ A $5 \mathrm{wt} \%$ cobalt catalyst was prepared using incipient wetness impregnation of $\mathrm{Co}\left(\mathrm{NO}_{3}\right)_{2} \cdot 6 \mathrm{H}_{2} \mathrm{O}$ dissolved in demiwater. After reduction in $\mathrm{H}_{2}$ at $350{ }^{\circ} \mathrm{C}$ for $2 \mathrm{~h}$ and passivation at $150{ }^{\circ} \mathrm{C}$ with $\mathrm{CO}_{2}$, manganese $(1 \mathrm{wt} \%)$ was deposited onto the $\mathrm{Co} / \mathrm{CNF}$ sample using wet impregnation of $\mathrm{Mn}\left(\mathrm{NO}_{3}\right)_{2} \cdot 4 \mathrm{H}_{2} \mathrm{O}$ followed by an optional reduction and passivation treatment under conditions mentioned. Using similar techniques a $12 \mathrm{wt}^{\%} \% \mathrm{Co} / \mathrm{CNF}$ catalyst was prepared and was impregnated with manganese loadings of $0.15,0.60,1.2$ and $2.4 \mathrm{wt} \%$ to obtain more detailed catalytic data.

The $5 \mathrm{wt} \%$ Co-loaded samples were examined in a dedicated scanning transmission electron microscope (STEM), VG HB501, with a Gatan Enfina spectrometer to obtain energy electron loss spectroscopy (EELS) spectra. High Angle Annular Dark Field (HAADF) images were acquired at an acceptance angle of 70 $210 \mathrm{mrad}$. XPS data were obtained with a Vacuum Generators XPS system using $\mathrm{Al} \mathrm{K}_{\alpha}$ radiation. FT-catalytic measurements, after re-reduction at $350{ }^{\circ} \mathrm{C}$, were carried out at $220{ }^{\circ} \mathrm{C}$ in a plugflow reactor at $110 \mathrm{kPa}$ and $\mathrm{CO} / \mathrm{H}_{2}(1: 2$, no diluents) as described earlier. ${ }^{3}$

Fig. 1 shows a representative dark field image together with elemental maps for cobalt, manganese and oxygen of the dried

\footnotetext{
*k.p.dejong@chem.uu.nl
}

$\mathrm{CoMn} / \mathrm{CNF}$ sample $(5 \mathrm{wt} \% \mathrm{Co}, \mathrm{Co}: \mathrm{Mn}=5: 1)$. Nanoparticles of 4-7 nm can clearly be seen to be decorating the fiber. The elemental mappings, abstracted from the EELS data, show that these particles consist of both cobalt oxide and manganese oxide. It is clear from the data that manganese is always associated with cobalt and is not found elsewhere. From comparing Fig. 1c and 1d it can be concluded that the Mn patches are bigger than the Co ones, suggesting that $\mathrm{Mn}$ is covering cobalt. This finding was supported by XPS data, as we found a $24 \%$ decrease of the $\mathrm{Co} / \mathrm{C}$ ratio upon loading of $1 \mathrm{wt} \% \mathrm{Mn}$. TEM investigations verified that this decrease had not been provoked by sintering of the cobalt particles. Since equal coverage of carbon and cobalt by manganese would increase the XPS $\mathrm{Co} / \mathrm{C}$ ratio, this indicates that also on a macroscopic scale manganese covers the cobalt particles. The absence of manganese on the CNF seems to be surprising as this metal was deposited after loading of cobalt, in principle allowing the manganese precursor to be deposited anywhere on the surface. This interesting observation can only be explained if a driving force can be identified for the coalescence of both metal oxides. A driving force that is very probable is the stabilisation of the manganese precursor on the cobalt oxide. Co and Mn have similar ionic radii and form both stable mixed nitrates and mixed oxides. In the drying step manganese nitrate is mobile and its deposition on cobalt is energetically favourable and hence likely.

The reader has to be aware that all measurements described so far were done on the dried, as synthesized catalyst. But before use in the FT reaction catalysts are reduced again which on an oxidic support causes segregation of both metals. ${ }^{6,7}$ Therefore, we also investigated the $\mathrm{CoMn} / \mathrm{CNF}$ sample reduced at $350{ }^{\circ} \mathrm{C}$. With quantitative XPS after in situ reduction no changes in the $\mathrm{Mn} / \mathrm{C}$ and the $\mathrm{Co} / \mathrm{C}$ ratios were found, showing the absence of sintering. Interestingly we observed a higher $\mathrm{Co}$ binding energy for the promoted system, which indicates that $\mathrm{MnO}_{x}$ retards the reduction of Co. Also EELS data (Fig. 2) showed that on the final catalyst $\mathrm{MnO}$ has not migrated to the support and is still present closely associated with the cobalt particles. Therefore, loading with $\mathrm{MnO}$ is to be expected to influence the catalytic properties of $\mathrm{Co} / \mathrm{CNF}$. Measuring at 2\% CO conversion, the selectivity towards longer hydrocarbons $\left(\mathrm{C}_{5+}\right)$ was found to increase substantially from 29 to $47 \mathrm{wt} \%$, mainly at the expense of undesired methane production which decreased from 44 to $22 \mathrm{wt} \%$. Furthermore it was found that the activity of the catalyst decreased from 1.64 to $0.3610^{-5} \mathrm{~mol}_{\mathrm{CO}} / \mathrm{g}_{\mathrm{Co}}{ }^{*} \mathrm{~s}$.

To investigate more systematically the effect of $\mathrm{MnO}$ on the catalytic performance of $\mathrm{Co} / \mathrm{CNF}$ catalysts we loaded various amounts of $\mathrm{Mn}$ on a $12 \mathrm{wt} \% \mathrm{Co} / \mathrm{CNF}$ catalyst described earlier. ${ }^{3}$ Fig. 3 shows the $\mathrm{C}_{5+}$ selectivity steadily increasing from 24 to 


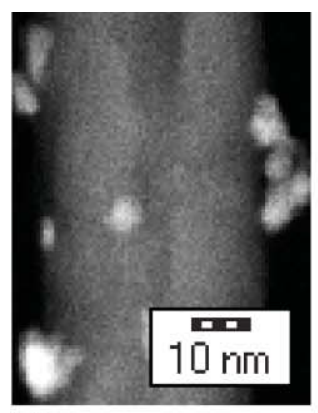

(a)

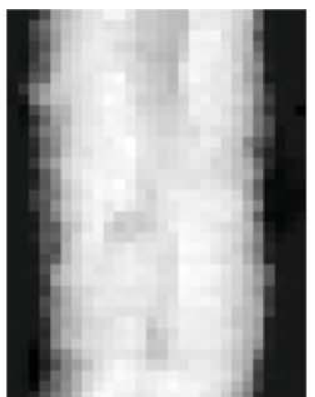

(b)

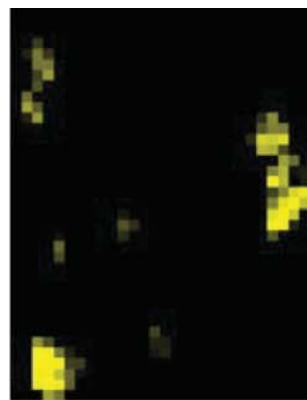

(c)

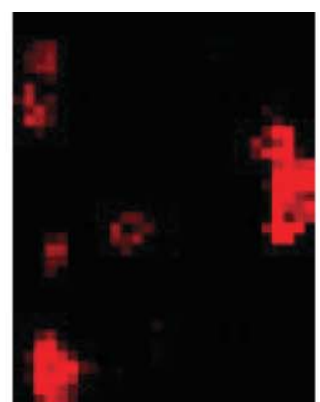

(d)

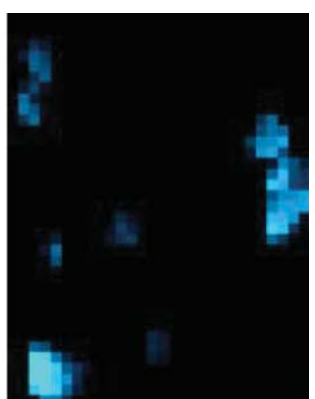

(e)

Fig. 1 Representative images of dried CoMn/CNF: (a) HAADF image and elemental mappings for (b) carbon, (c) cobalt, (d) manganese and (e) oxygen.

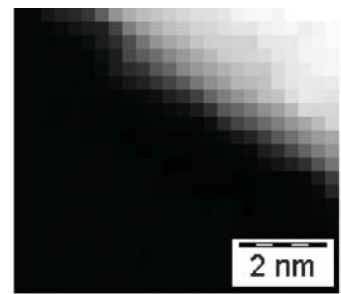

(a)

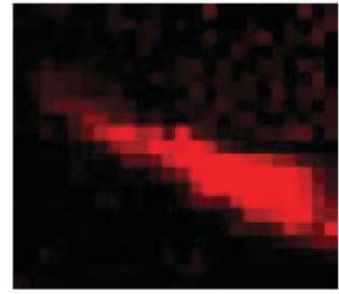

(c)

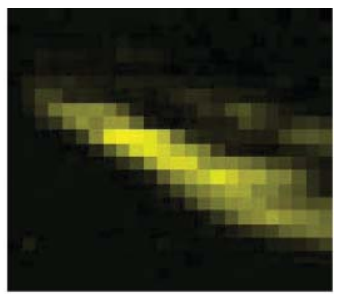

(b)

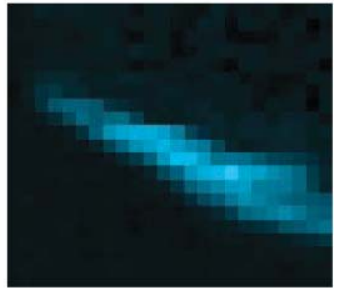

(d)
Fig. 2 Elemental mappings for $\mathrm{CoMn} / \mathrm{CNF}$ reduced at $350{ }^{\circ} \mathrm{C}$ : (a) carbon, (b) cobalt, (c) manganese and (d) oxygen.

$51 \mathrm{wt} \%$ with increasing manganese loading, while the methane selectivity decreased from 44 to $17 \mathrm{wt} \%$. The activity, expressed as the yield of $\mathrm{C}_{5+}$, goes through a maximum at a $\mathrm{Mn}$ loading of $0.15 \mathrm{wt} \%$. Higher loadings of Mn still increase the selectivity, but

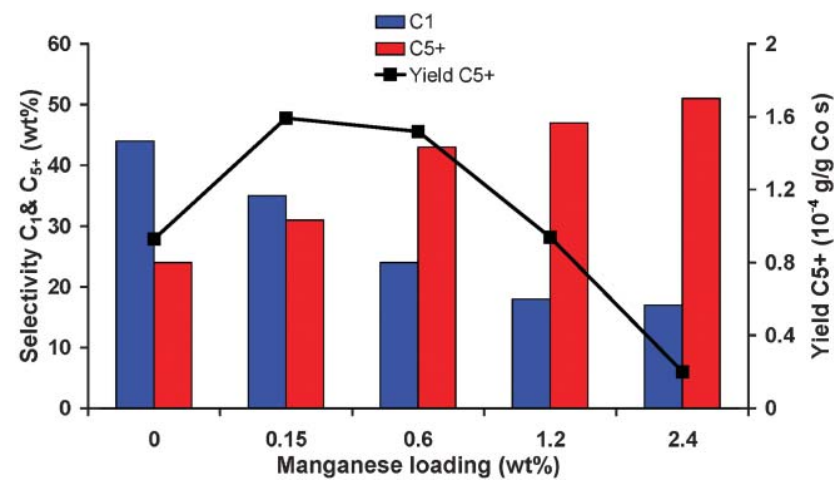

Fig. 3 Influence of Mn loading on selectivity and activity of $12 \mathrm{wt} \% \mathrm{Co} /$ $\mathrm{CNF}$, measured at $220{ }^{\circ} \mathrm{C}$, GHSV $=9400 \mathrm{~h}^{-1}$. Reported data are for stable performance after at least $48 \mathrm{~h}$ of operation. the activity decreases. It is likely that this decrease in activity with higher Mn loading stems from the blocking of cobalt surface sites, which previously were active in the FT reaction. The cobalt atoms in the vicinity of $\mathrm{MnO}_{x}$ have a lower hydrogenation activity and hence become more selective towards $\mathrm{C}_{5+}$ formation. So both the catalytic data and the data obtained from characterisation with STEM-EELS and XPS point towards the covering of cobalt by $\mathrm{MnO}_{x}$.

$\mathrm{MnO}_{x}$ is reported to be a promoter element for cobalt-based FT catalysts in both academic and patent literature. Originally most of the research was devoted to cobalt supported on $\mathrm{MnO}_{2}$ supports. ${ }^{8-11}$ All of these systems have high manganese loadings and the increased selectivity towards longer hydrocarbons might be comparable to the widely studied strong metal support interaction (SMSI). SMSI is observed for catalysts supported on titania and is provoked by the migration of $\mathrm{TiO}_{x}$ sublayers onto the metallic particles. ${ }^{12,13}$ Recently $\mathrm{MnO}_{x}$ promoter effects on cobalt catalysts supported on oxidic carriers have been investigated. ${ }^{6,7,14-17}$ Very recently Morales et al. fundamentally studied promoter effects on $\mathrm{Co} / \mathrm{TiO}_{2}$ doped with $\mathrm{Mn}(\mathrm{Co} / \mathrm{Mn}=3.5)$. ${ }^{6,7}$ The authors report lower cobalt reducibility to be responsible for increased selectivity towards longer hydrocarbons (from 28 to $35 \mathrm{wt}^{\%} \%$ ). Interestingly they report migration of $\mathrm{MnO}_{x}$ to the titania support during the reduction treatment. We showed that the study of promoter effects can benefit a lot from the use of inert carriers like $\mathrm{CNF}$ as even after reduction the promoter is not found separately on the CNF surface. Therefore the addition of very small amounts of $\mathrm{Mn}(0.15 \mathrm{wt} \%)$ already brought about a $25 \%$ increase of $\mathrm{C}_{5+}$ selectivity. The link we found between promoter addition, characterisation and catalysis will be of use for the discovery of advanced cobalt based FT catalysts. We propose that the study of other oxidic promoters can benefit from the use of $\mathrm{CNF}$ as support material.

We thank A. J. M. Mens for performing the XPS measurements, D. T. Foord for help with EELS dataprocessing and Shell Global Solutions for financial support.

G. Leendert Bezemer, ${ }^{a}$ Uwe Falke, ${ }^{b}$ A. Jos van Dillen ${ }^{a}$ and Krijn P. de Jong* $*^{a}$

${ }^{a}$ Department of Inorganic Chemistry and Catalysis, Debye Institute, Utrecht University, Sorbonnelaan 16, 3584 CA, Utrecht, The Netherlands. E-mail: k.p.dejong@chem.uu.nl; Fax: +31 30251 1027; Tel: +31 302536762

${ }^{b}$ UK SuperSTEM, Daresbury Laboratory, Daresbury, UK WA4 4AD. E-mail:falke@horst.in-chemnitz.de; Fax: +44 192586 4910; Tel: +441925864905 


\section{Notes and references}

1 K. P. de Jong and J. W. Geus, Catal. Rev.-Sci. Eng., 2000, 42, 481.

2 P. Serp, M. Corrias and P. Kalck, Appl. Catal., A: Gen., 2003, 2, 337.

3 G. L. Bezemer, A. van Laak, A. J. van Dillen and K. P. de Jong, Stud. Surf. Sci. Catal., 2004, 147, 259.

4 M. L. Toebes, J. H. Bitter, A. J. van Dillen and K. P. de Jong, Catal. Today, 2002, 1, 33.

5 M. L. Toebes, E. M. P. van Heeswijk, J. H. Bitter, A. J. van Dillen and K. P. de Jong, Carbon, 2004, 42, 307.

6 F. Morales, O. L. J. Gijzeman, F. M. F. de Groot and B. M. Weckhuysen, Stud. Surf. Sci. Catal., 2004, 147, 271.

7 F. Morales, F. M. F. de Groot, O. L. J. Gijzeman, A. Mens, O. Stephan and B. M. Weckhuysen, J. Catal., in press.

8 M. Van der Riet, G. J. Hutchings and R. G. Copperthwaite, J. Chem. Soc., Chem. Commun., 1986, 798.
9 S. E. Colley, R. G. Copperthwaite, G. J. Hutchings, S. P. Terblanche and M. M. Thackeray, Nature, 1989, 339, 6220.

10 K. Guse and H. Papp, Fresenius' J. Anal. Chem., 1993, 346, 84.

11 M. J. Keyser, R. C. Everson and R. L. Espinoza, Appl. Catal., A: Gen., 1998, 171, 99.

12 S. J. Tauster, Acc. Chem. Res., 1987, 11, 389.

13 M. A. Vannice and R. L. Garten, J. Catal., 1979, 56, 236.

14 J. J. C. Geerlings, M. F. Goes, H. M. Huisman, J.-P. Lange, H. Oosterbeek, P. J. M. Rek and D. Schadenhorst, WO9700231 Patent, 1997.

15 Y.-Q. Zhang, B. Zhong and Q. Wang, J. Nat. Gas Chem., 1997, 6, 275.

16 M. Johns, P. Landon, T. Alderson and G. J. Hutchings, Chem. Commun., 2001, 2454.

17 M. Jiang, N. Koizumi, T. Ozaki and M. Yamada, Appl. Catal., A: Gen., 2001, 209, 59 . 